\title{
EXPERIMENTAL STUDY ON THE DISCHARGE CHARACTERISTICS OF SLUICE FOR TIDAL POWER PLANT
}

\author{
Sang-Ho Oh ${ }^{1}$, Kwang Soo Lee ${ }^{1}$ and Dal Soo Lee ${ }^{1}$
}

\begin{abstract}
The discharge characteristics of sluice caisson for tidal power plant were investigated by carrying out a physical experiment in a planar open channel. The experiment was performed by installing 10 sluice models whose scale was $1 / 70$ of the prototype in the planar open channel, where apron sections were made in front of and behind the sluice models to reproduce the field condition. The locations and method of measuring water levels were carefully determined so as to accurately estimate the discharge coefficient, an index of representing the discharge performance of the sluice caisson. The experimental results for various conditions of flow rates and water levels showed that the discharge coefficient of the sluice caisson was in the range of 1.3 to 1.47 . These values were substantially smaller than those obtained from the previous study performed in a two-dimensional open channel (Lee et al., 2010). As the previous study had some limitations in reproducing the bathymetric and flow conditions in the field, it is more recommended to use the results acquired in the present experiment.
\end{abstract}

Keywords: Tidal power plant; Sluice caisson; Discharge performance; Apron; Planar open channel

\section{INTRODUCTION}

Tidal energy resources are very abundant on the western coast of Korean peninsula, where a 254 MW tidal power plant was constructed in Sihwa Lake (Bae et al., 2010) and are commercially being operated since 2011 (See Figure 1). In addition, several feasibility studies are being carried out for possible construction of another tidal power plant around the region (Yum et al., 2007). The sluice of tidal power plant is one of factors that are closely associated with the efficiency of tidal power generation. The main role of the sluice is introducing as many waters through it so as to achieve target capacity of the power generation. In this respect, Lee et al. (2010) investigated the characteristics of water discharge according to geometrical shape of the sluice in order to maximize the water discharge performance of the structure. Their study had some limitations in evaluating the performance of the sluice as they made experiments with a single sluice caisson in a two-dimensional open channel. In addition, all the tests in the previous experiment were made with a flat bottom surface around the sluice caisson, which is hardly found in the field condition. In this respect, physical experiments in the present study were performed in a planar open channel in order to examine the discharge performance of the sluice caisson under flow conditions involving three dimensional effects as well as the change in bottom topography.

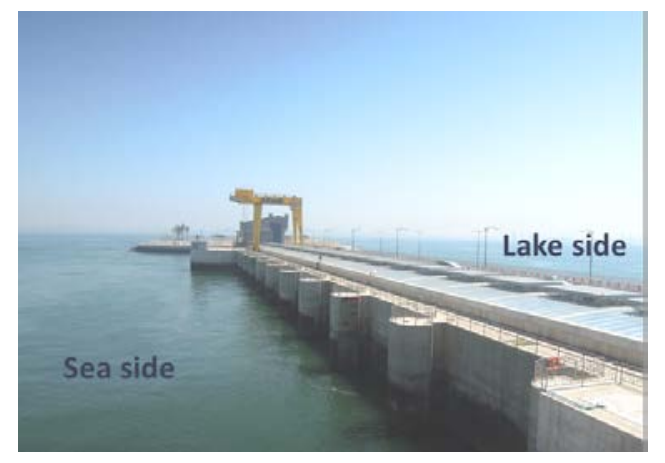

Figure 1. Sihwa tidal power plant in Korea.

\section{PHYSICAL EXPERIMENTS}

\subsection{Experimental Setup}

The experiments were carried out in a planar open channel of $23.6 \mathrm{~m}$ long, $16 \mathrm{~m}$ wide and $1.0 \mathrm{~m}$ high. The height of the channel bottom was $0.5 \mathrm{~m}$ from the ground. At the end of the channel, a

\footnotetext{
${ }^{1}$ Coastal Development \& Ocean Energy Research Department, Korea Institute of Ocean Science \& Technology, 787 Haeanro, Ansan, 426-744, Republic of Korea
} 
rotationally moving weir was installed to control the flow rate in the channel. The sluice caisson designed for the feasibility study of the Incheon tidal power plant project was adopted in the experiment. The scale of the model was determined to be $1 / 70$ of the prototype considering the overall experimental conditions. As shown in Figures 2 and 3, 10 pieces of the sluice caisson models as well as two connecting structures were made of acryl and installed in the open channel. The bottom topography in front of and behind the model structures was formed as 1:10 slope apron, which was a transition section between the ambient sea bottom and the bottom where the sluice caissons were installed. The sluice caisson models were placed at $10.0 \mathrm{~m}$ downstream from the inlet of the test section, which was almost the half point of the total length of the open channel.

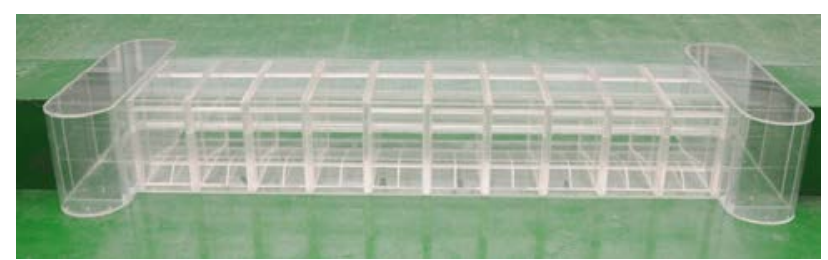

Figure 2. sluice caissons and connecting structures made of acryl.

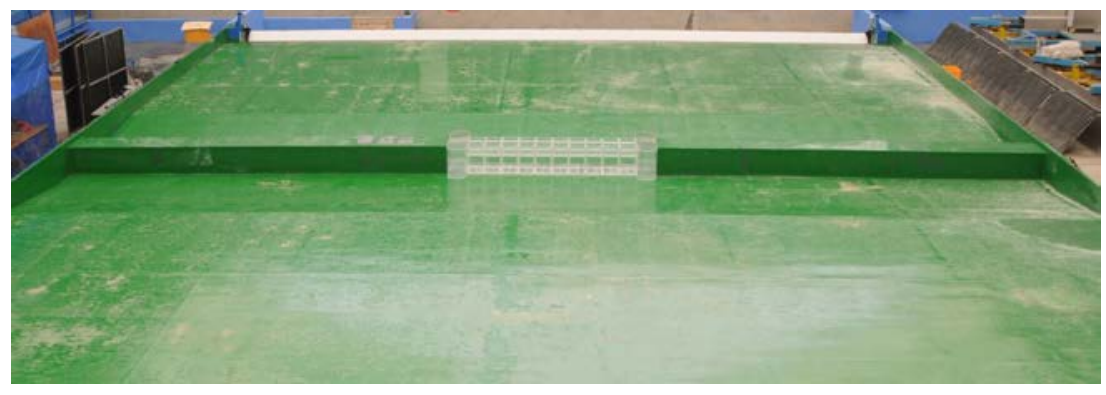

Figure 3. General view of the planar open channel after installation of 10 sluice caissons.

\subsection{Experimental conditions}

The experimental conditions were determined based on the numerical simulation performed in the feasibility study of the Incheon tidal power plant. By analyzing the simulation results, the probability distribution of the sea water level and the corresponding difference in water levels between the sea and basin were obtained as shown in Figure 4.
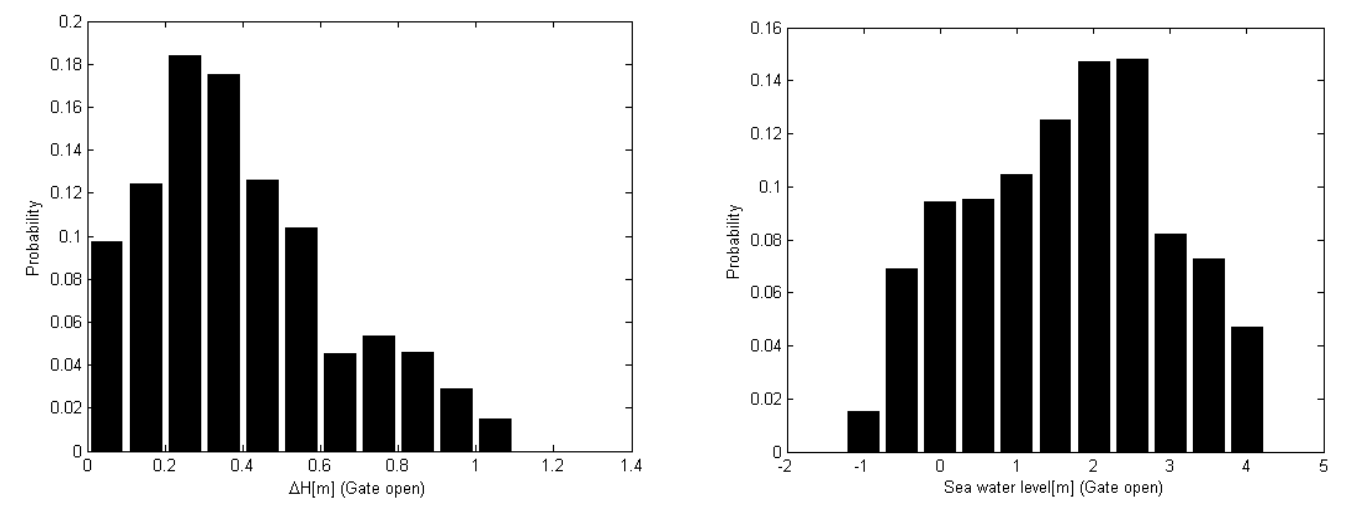

Figure 4. Normalized histogram for the sea water level and the water level difference (field condition).

By utilizing this information, the experiment was carried out with a total of 18 different experimental conditions of six different flow rates and three different water levels. The values of water discharge rate (Q) were 400, 520, 640, 770, 890, $1070 \mathrm{~m}^{3} / \mathrm{sec}$, whereas the water level at the upstream 
of the sluice varied as EL. $( \pm) 0.0 \mathrm{~m}$, EL. $(+) 1.5 \mathrm{~m}$, EL. $(+) 3.0 \mathrm{~m}$. Note that these experimental conditions were corresponding to the values in the field. In order to keep the experimental condition being changed little during the measurement, a careful effort was made in the control of the water supply system and the operation of the weir at the channel end.

The water discharge rate was estimated by using the electro-magnetic flow meter attached to the water supply pipe. Meanwhile, the water levels in the open channel were measured by using a total of 10 acoustic point gauges. Among them, five gauges were placed $1 \mathrm{~m}$ upstream from the starting point of the front apron slope whereas the rest five were located $4 \mathrm{~m}$ downstream from the end of the rear apron slope. The locations for measuring water levels were determined based on intensive measurements by varying the measuring locations, details of which are described in the sections 3.2 and 3.3. At each measuring location, the water level was measured three times consecutively and the final water level was obtained by taking the mean of the three values. If the three values showed prominent fluctuation or trend, the water level was measured again from the first by discarding the measured values.

\section{DETERMINATION OF THE MEASURING LOCATIONS}

\subsection{Significance of water level measurement}

As an index of assessing the water discharge capability of the sluice caisson, discharge coefficient $\left(C_{d}\right)$ is typically used that is defined as follows (Baker, 1991):

$$
C_{d}=\frac{Q}{A_{t} \sqrt{2 g \Delta H}}
$$

where, $A_{t}$ is the area of the throat section, $g$ is the gravitational acceleration, and $\Delta H$ is the head difference between both sides of the sluice caisson defined as

$$
\Delta H=\left(h_{u p}+\frac{V_{u p}^{2}}{2 g}\right)-\left(h_{d n}+\frac{V_{d n}^{2}}{2 g}\right)+h_{f}
$$

In Equation (2), $V_{u p}$ and $V_{d n}$ are the mean velocities on upstream and downstream of the sluice caisson, respectively, which is typically calculated by dividing the water discharge rate with the respective crosssectional area. The symbol of $h_{f}$ denotes the head loss in the open channel, which was taken into account to compensate the natural gradient of the mean water level in the channel. In this study, the magnitude of $h_{f}$ was estimated by comparing the measurement results of the mean water levels along the channel with and without installing the sluice caisson model.

As seen in Equation (1), the discharge coefficient is inversely dependent on the head difference, which is greatly affected by the locations of measuring water levels upstream and downstream of the sluice caisson. With regard to the determination of the measuring location, however, little references or literatures are available. Hence, intensive measurement and analysis were carried out in order to reasonably decide the measuring locations that could affect the evaluation of the discharge performance of the sluice caisson.

\subsection{Streamwise profiles of the mean water level}

First, the streamwise water levels were measured at 19 locations along the centerline of the open channel as shown in Figure 5. The result of the measurement shown in Figure 6 provides information about spatial variation of the mean water levels along the measurement transect. The horizontal axis in Figure 6 denotes the distance in streamwise direction that is calculated from the front wall of the sluice caissons, while the vertical axis the mean water level acquired at each of 19 locations $\left(w_{i}\right)$ extracted by the mean water level at the 10th location just at the front wall of the sluice caisson $\left(w_{s c}\right)$.

The spatial variation of the mean water level showed marked difference on caisson upstream and downstream as clearly seen in Figure 6. On upstream of sluice caissons, no significant change in water levels was found except the almost linearly varying slight gradient that was naturally formed with the flow in the open channel. Since the lateral distribution of the mean water level would be more stabilized with the increase in water travelling distance from the inlet of the water supply system, the last location on sluice upstream outside the bottom transition section was considered as the most desirable position for representing the water level on upstream. At the three measurement locations within the transition section on sluice upstream, temporal fluctuation of water level was larger than the rest seven locations further upstream, probably influenced by the change in flow field due to the change in bottom 
topography in the transition section. In this respect, the final location for evaluating the mean water level on the sluice upstream was determined to be $1 \mathrm{~m}$ upstream from the end of the flat bottom section.

Meanwhile, similar measurement was carried out without installation of the sluice caissons in order to compare with the case when the structures were not installed in the open channel. As shown in Figure 7 , the gradient and fluctuation of the mean water level were greatly reduced in this situation. By analyzing difference in the measurement results of the mean water level between the two cases, it was possible to estimate the head loss $\left(h_{f}\right)$ that was used in the evaluation of the head difference $(\Delta H)$.

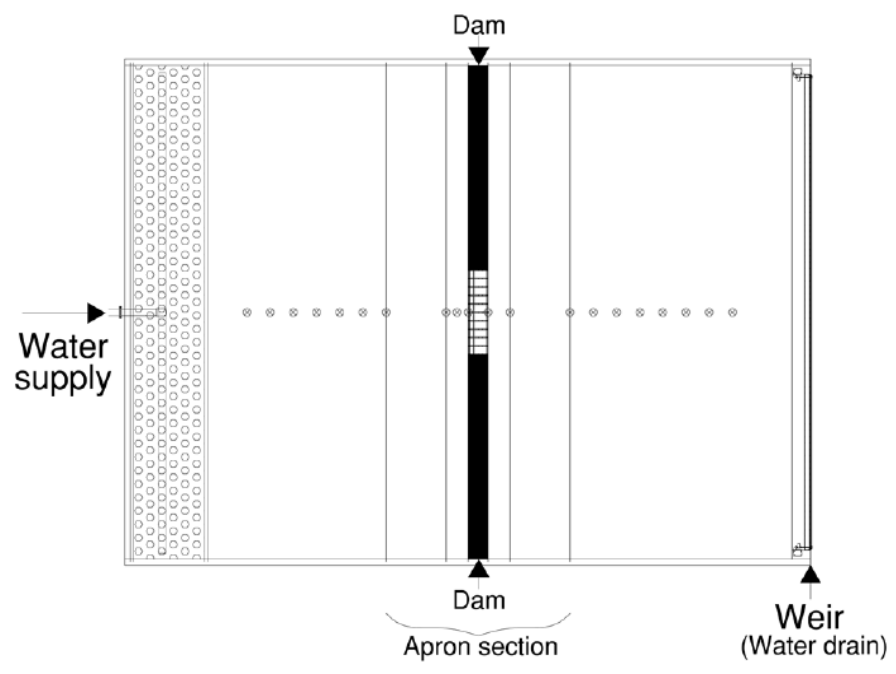

Figure 5. Locations for measuring streamwise variation of water levels.

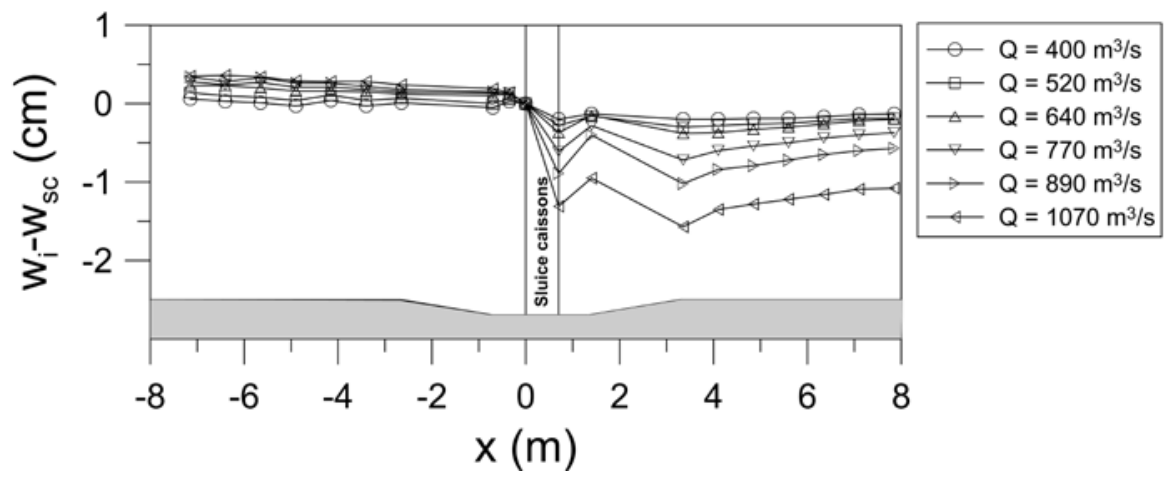

Figure 6. Streamwise variation of the mean water levels with installation of sluice caissons.

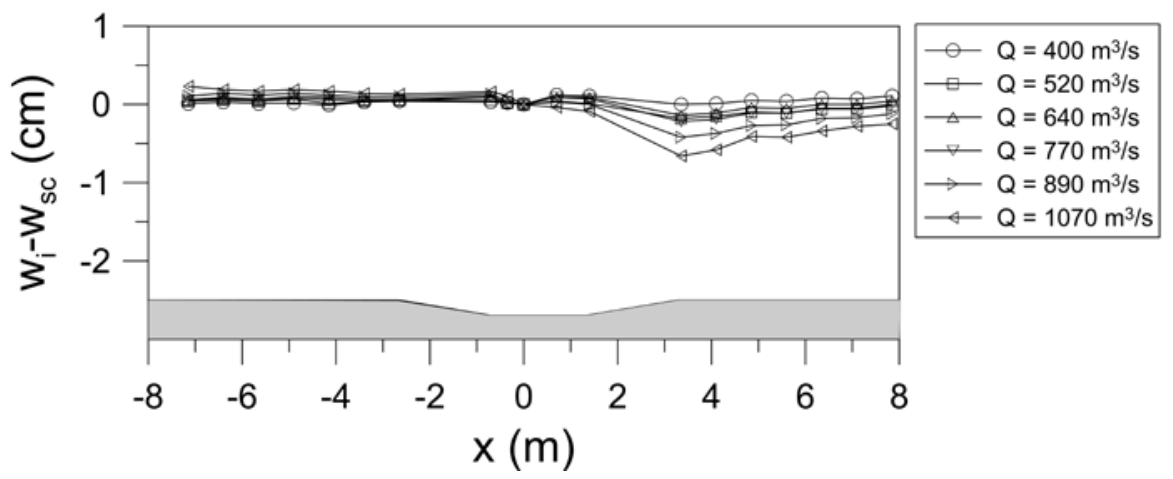

Figure 7. Streamwise variation of the mean water levels without installation of sluice caissons. 


\subsection{Lateral profiles of the mean water level}

As shown in Figure 6, the mean water level greatly fluctuated on sluice downstream, especially when the flow rate was large. This drastic variation in the mean water level was originated from the discontinuity in the cross-section of flow passage at the rear wall of the sluice caissons. The water mass passing though inside the sluice caissons is released to widely open space just behind the structures so that the flow pattern just behind the caissons looked like water jets. As the jet-like fast flows are suddenly decelerated on sluice downstream, the water surface greatly undulated, which in turn invoke the large variation of the mean water level. Due to the high spatial and temporal oscillation of water surface behind the sluice caisson, it was not easy to determine the proper measuring locations, where the measured mean water level would be used for estimation of the head difference. By considering this, water surface levels were measured at the five transects in lateral direction, starting from the end of apron transition section to $4 \mathrm{~m}$ further downstream at an interval of $1 \mathrm{~m}$, as shown in Figure 8 . In addition, the measurement was carried out at the five different positions at an interval of $2 \mathrm{~m}$ along each of the lateral transects, ranging from $-4 \mathrm{~m}$ to $4 \mathrm{~m}$ with respect to the centerline of the channel.

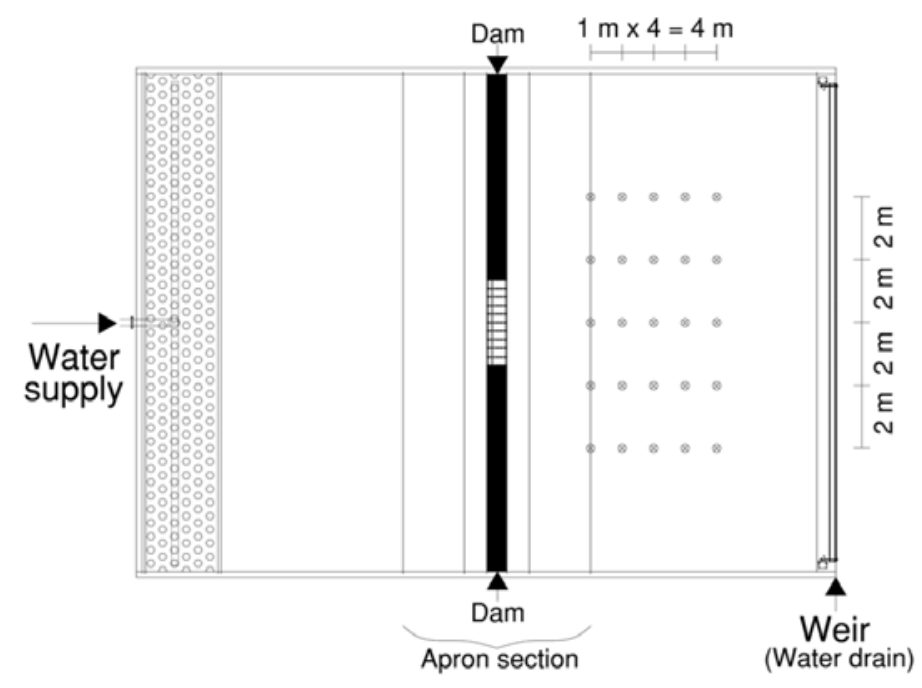

Figure 8. Locations for measuring lateral variation of water levels.

The results of this measurement are shown in Figure 9, where the transverse variation of the mean water level along each of the five transects is shown respectively. In the figure, the horizontal axis denotes the transverse distance from the channel centerline, whereas the vertical axis the mean water level at each of the individual measuring locations $\left(w_{i}\right)$ extracted by the mean water level at the central location $\left(w_{c}\right)$. As shown in the figure, the lateral distribution of the mean water level became less fluctuated with the increase of water travelling distance on the sluice downstream. At the first transect behind the sluice caisson, significant difference in the mean water level was observed between the centerline and both edges. In particular, the discrepancy in the mean water level was noticeably huge when the flow rate was large. As the flow travelled further downstream, such difference became gradually smaller, but it was still not negligible, greater than $1 \mathrm{~mm}$, at $x=6.35 \mathrm{~m}$, or $3 \mathrm{~m}$ downstream from the apron end. The fluctuation merely became less than $0.5 \mathrm{~mm}$ at further $1 \mathrm{~m}$ downstream $(x=$ $7.35 \mathrm{~m}$ ), which was reasonably acceptable for evaluating the mean water level. Based on this observation, the final location for evaluating the mean water level on the sluice downstream was determined to be $4 \mathrm{~m}$ downstream from the apron end.

In Figure 10, the final measuring locations adopted for the evaluation of the mean water level are shown. On the sluice upstream, water surface levels were measured at the five locations along the lateral transect at $1 \mathrm{~m}$ upstream from the starting point of the former apron. Meanwhile, the water level measurement was carried out at $4 \mathrm{~m}$ downstream from the latter apron end on the sluice downstream. The final mean water level was determined by taking the spatial average of the mean water level at the five locations on both sides, respectively. 

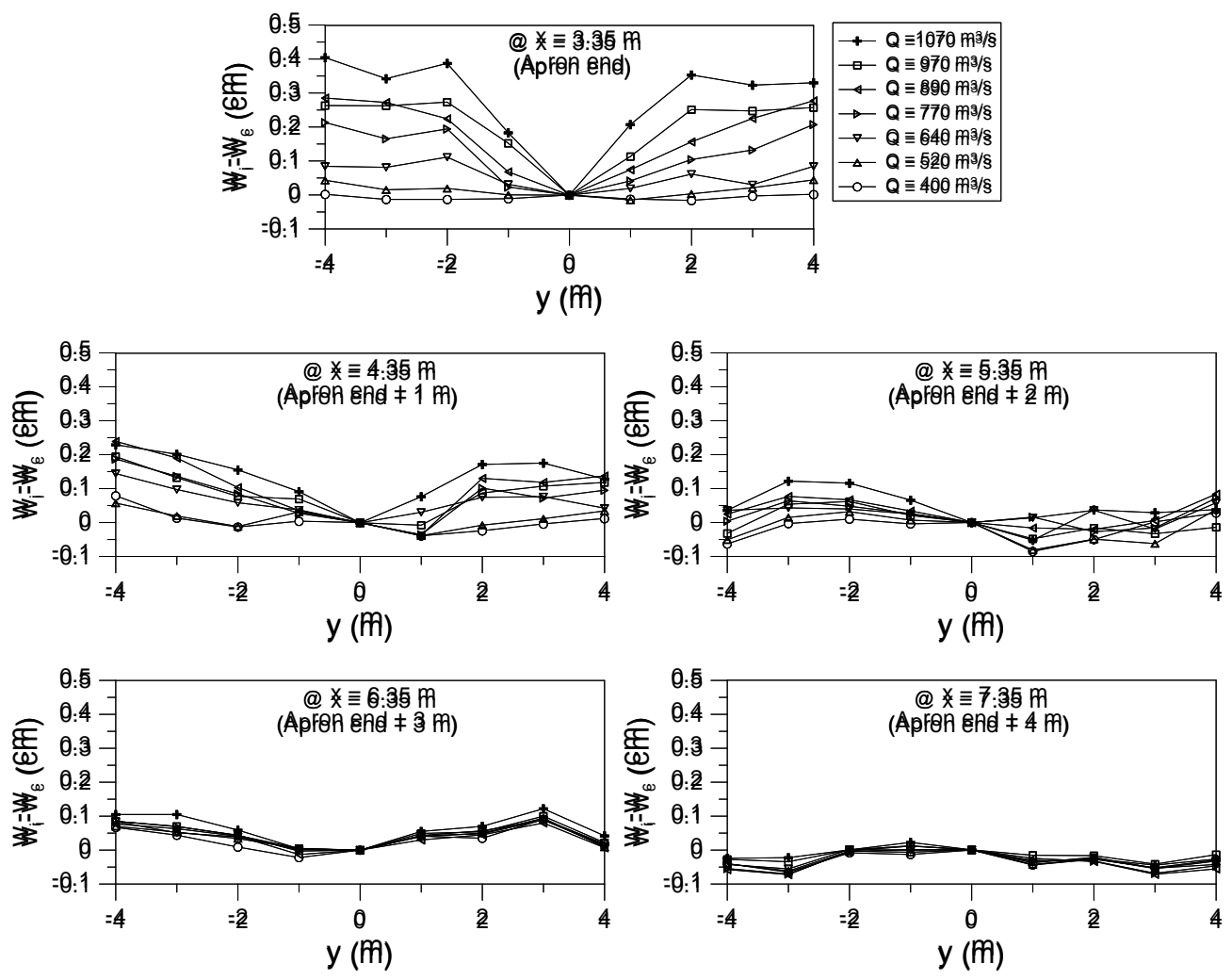

Figure 9. Lateral variation of the mean water levels in the planar open channel.

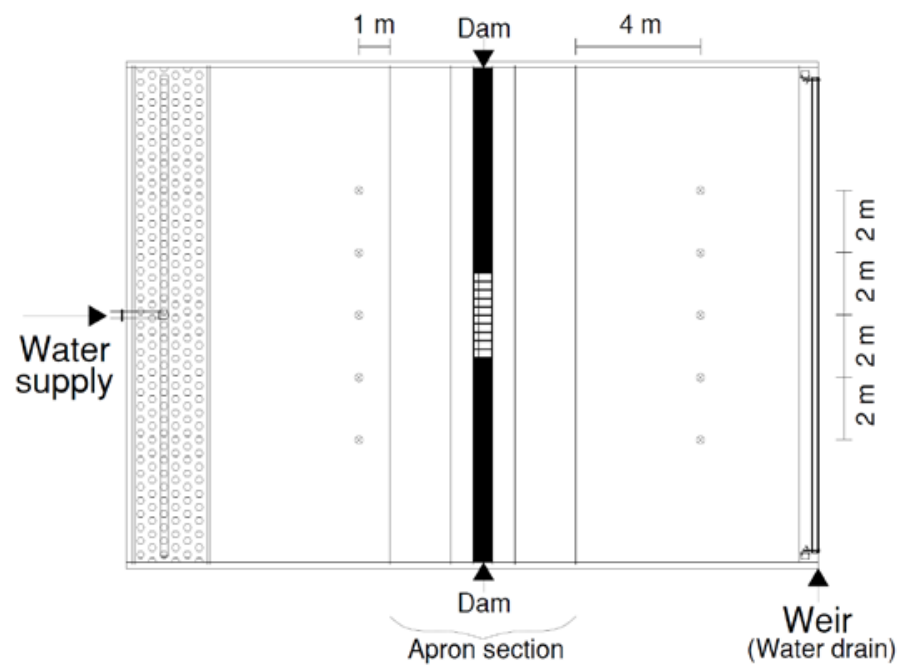

Figure 10. Final measuring locations used for evaluating the mean water level.

\section{Estimation of the discharge performance}

By analyzing the measured data obtained at the 10 locations shown in Figure 10, the head difference between sluice upstream and downstream was calculated for all the test conditions of different flow rates and water levels. The left panel of Figure 11 shows the relationship of the flow rate with regard to the head difference. Note that the physical quantities in the figure are corresponding to the field condition. As shown in the left figure, the flow rate had a proportional relationship with the head difference. This implies that the head difference becomes greater as the flow rate passing through the sluice caisson increases. Another characteristic found in the figure is that the difference in flow rate was only marginal with respect to the upstream water level $\left(h_{u p}\right)$. 
Meanwhile, the estimated discharge coefficients are presented as a function of the head difference in the right panel of Figure 11. It is clearly seen that the values showed no significant functional relationship with the head difference. On average, the discharge coefficient ranged from 1.3 to 1.47, which was apparently smaller than the values of the same quantity obtained from the previous study (Lee et al., 2010), where the coefficient was mostly greater than 2.0. The reason for this substantial discrepancy is ascribed to the difference between the experimental conditions of the two experiments. In the previous experiment, the measurement was performed in a two-dimensional open channel by placing the sluice caisson on the flat bottom of the channel, which was completely different from the setup of the present experiment. In addition, only one sluice caisson was placed in the channel with no significant change in cross-sectional area in front of and behind the sluice, contrary to the present experiment. It seems that the values in the previous study were estimated rather higher than the real situation in the field since its experimental setup was less similar to the field condition. In this respect, it is preferable to assess the discharge coefficient of the sluice by performing a three-dimensional experiment, especially when the geophysical variation around the sluice caisson is significant. Hence, the use of discharge coefficient obtained in the present experiment is more recommended as the bathymetric and flow conditions were closer to those encountered in the field.
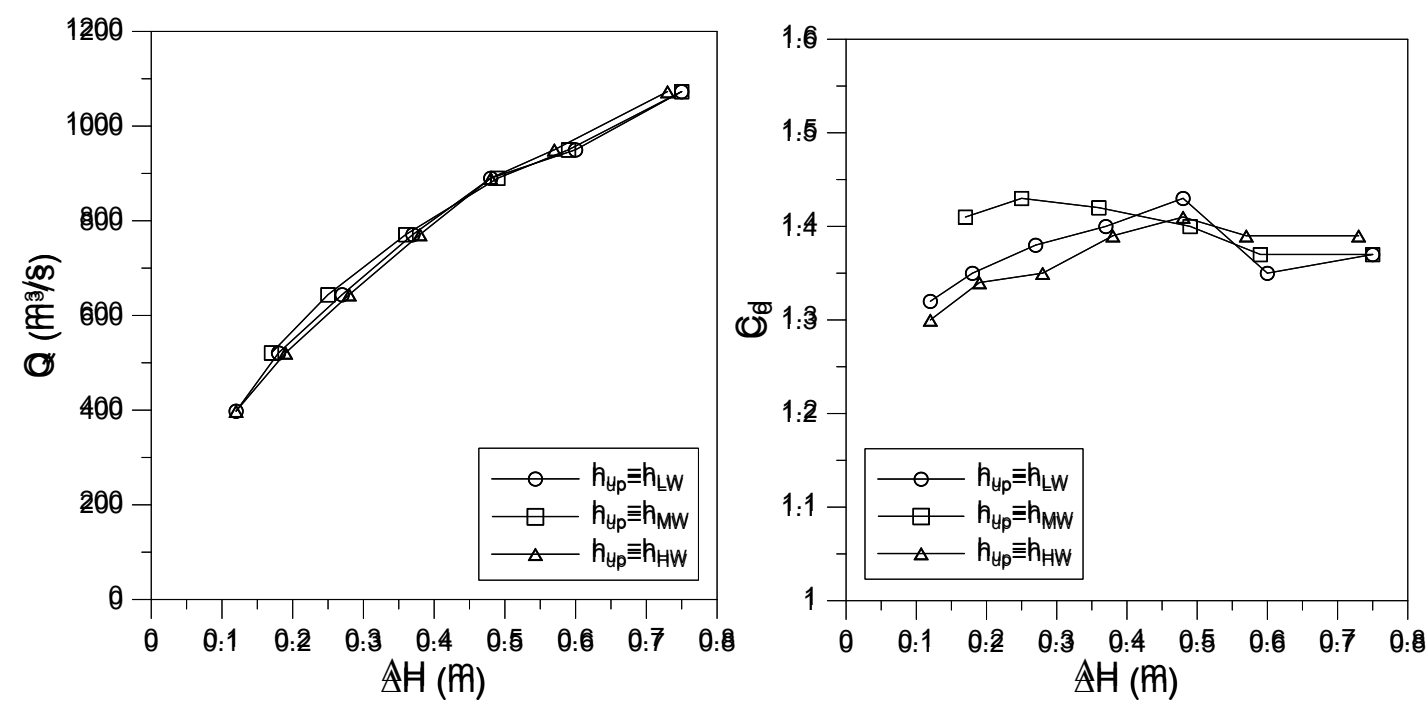

Figure 11. Values of $Q$ and $C_{d}$ as a function of $\Delta H$.

\section{CONCLUSION}

The results of experimental research for assessing the performance of the sluice caisson adopted for the tidal power plant are presented in this study. By carrying out a laboratory experiment with a 1/70 scale of the sluice caisson models including the effects of bottom surface undulation as well as change in transverse dimension, it was possible to quantitatively investigate the discharge performance of the sluice caisson under the condition similar to the field. By recognizing the influence of the head difference, which could be affected to some extent by the measurement of the mean water levels upstream and downstream of sluice caisson, on the estimation of the discharge coefficient, reasonable method of evaluating the head difference in the physical experiment was suggested.

The experimental results showed that the average discharge coefficient ranges from 1.3 to 1.47 , which was approximately $30 \%$ smaller than the value obtained from the similar previous experiment (Lee et al., 2010) performed in a two-dimensional open channel. This difference was presumed to be influenced by the two factors with regard to the change in bottom topography and the dimensional effects in lateral direction. In the present experiment, the channel bottom surface was not flat as in the previous experiment but varied as the bottom transition sections including sloped apron were placed in front of and behind the sluice caisson. Another distinction was that the present experiment was carried out in the three-dimensional open channel which allowed drastic sudden shrink and extension in the cross-sectional area for flow passage at the inlet and outlet of sluice caissons respectively that could not be reproduced in a two-dimensional open channel. The velocity field approaching to the sluice inlet would be different in the two experiments, which in turn significantly affects the general discharge 
performance of the sluice caisson. By considering this intrinsic discrepancy between the both studies, it was concluded to apply results of the present experiment for practical design of the sluice caisson if the bathymetric and flow conditions in the field are similar to those in the experiment.

\section{ACKNOWLEDGMENTS}

This research was supported by KIOST (Korea Institute of Ocean Science and Technology) research program (project No. PE98763).

\section{REFERENCES}

Baker, A.C. 1991. Tidal Power, Peter Peregrinus Ltd., London, United Kingdom, 250 pp.

Bae, Y.H., Kim, K.O., Choi, B. H. 2010. Lake Sihwa tidal power plant project, Ocean Engineering, 37, 454-463.

Lee, D.S., Oh, S.-H., Yi, J.-H., Park, W.-S., Cho, H.-S., Kim, D.-G., Eom, H.-M., Ahn, S.-J. 2010. Experimental Investigation on the relationship between sluice caisson shape of tidal power plant and the water discharge capability, Renewable Energy, 35, 2243-2256.

Yum, K.-D. 2007. Tide and tidal current energy development in Korea, Proceedings of Asian and Pacific Coasts 2007, 42-55. 